\title{
ethic \\ AUCTORITAS FACIT LEGEM: O PROBLEMA DA JUSTIFICAÇÃO DA AUTORIDADE EM HOBBES
}

\section{AUCTORITAS FACIT LEGEM: THE PROBLEM OF JUSTIFICATION OF AUTHORITY IN HOBBES}

\section{CLÓVIS BRONDANI ${ }^{1}$}

(UFFS/Brasil)

\begin{abstract}
RESUMO
Este texto objetiva tratar da relação entre ciência e autoridade na filosofia de Thomas Hobbes. O problema fundamental que motiva o trabalho está nas constantes afirmações de Hobbes segundo as quais é a autoridade e não a verdade que faz a lei. Tais afirmações, que revelam a adesão à concepção voluntarista de lei, parecem comprometer o projeto de instituição da scientia civilis por parte de Hobbes, uma vez que a decisão do soberano seria de caráter meramente arbitrário e não fundada racionalmente, portanto. Desta perspectiva, o projeto de fundar uma ciência da moral e da política parece perder grande parte de sua força, o que por sua vez torna problemático o estabelecimento de uma base normativa adequada para a autoridade política, uma vez que a justificação dos enunciados normativos que a fundamentam deveria necessariamente derivar do conhecimento científico. A intenção é elencar alguns elementos que possam demonstrar que a tese da auctoritas facit legem não implica o abandono da racionalidade, argumentando que não apenas a justificação da autoridade, mas a própria instauração da lei civil segue um conjunto de princípios racionais.
\end{abstract}

Palavras-Chave: Autoridade; Normatividade; Ciência civil; Soberania.

\begin{abstract}
This text aims to address the relationship between science and authority in Thomas Hobbes' philosophy. The fundamental problem that motivates this text lies in Hobbes' constant assertions that it is authority and not truth that makes the law. Such statements, which reveal adherence to the voluntarist conception of law, seem to compromise Hobbes' project of institution of scientia civilis, since the sovereign's decision would be of a merely arbitrary character and therefore not rationally founded. From this perspective, the project of founding a science of morals and politics seems to lose much of its strength, which in turn makes the establishment of an adequate normative basis for political authority problematic, since the justification of the normative statements that underlie it should necessarily derive from scientific knowledge. The intention is to list some elements that can demonstrate that the thesis of auctoritas facit legem does not imply the abandonment of rationality, proving that not only the justification of authority, but the establishment of civil law itself follows a set of rational principles.
\end{abstract}

Keywords: Authority; Normativity; Civil science; Sovereignity. 


\section{Introdução}

No capítulo XXVI do Leviatã, Hobbes afirma que a obrigatoriedade da lei não depende da suposta verdade descoberta pelos filósofos morais. Tal consideração aparece na versão Latina do livro sob a fórmula Sed Auctoritas Non Veritas Facit Legem, que se repete também no Diálogo entre um filósofo e um jurista (HOBBES, 2004, 37). A recorrente declaração dessa tese por parte de Hobbes parece, por vezes, comprometer o seu projeto de fundar uma "ciência política", conforme ele apresenta em sua proposta de construir um sistema filosófico que parte do princípio do movimento, passa pela física e chega até o conhecimento da política. ${ }^{2}$ Se levarmos a sério a tese segundo a qual a autoridade faz a lei, parece que as ordenações políticas não encontram fundamento na ciência, mas na decisão arbitrária do soberano, que impõe a lei não porque ela é uma espécie de verdade moral obtida a partir do método científico, mas por se tratar de uma decisão de sua vontade. ${ }^{3}$

Desta perspectiva, o projeto de fundar uma ciência da moral e da política parece perder grande parte de sua força, o que por sua vez torna problemático o estabelecimento de uma base normativa adequada para a autoridade política, uma vez que a justificação dos enunciados normativos que fundamentam autoridade política parece necessariamente derivar do conhecimento científico. Em última instância, se a legitimação da autoridade não deriva da verdade supostamente descoberta pelo método científico infalível proposto por Hobbes, mas meramente da autoridade constituída em si mesma, cabe perguntar qual seria propriamente o papel da ciência no projeto hobbesiano de fundar uma filosofia civil, não apenas no que diz respeito à justificação da normatividade política, mas também em relação à própria ação política do soberano. Neste sentido, a tese da auctoritas facit legem parece derivar numa concepção na qual não há um elemento racional que legitime as decisões da soberania além da própria autoridade que dela emana. Esta condição parece expressar um aspecto irracionalista na filosofia política de Hobbes que estaria em oposição ao seu projeto de fundar a política sobre o conhecimento científico.

Neste sentido, segundo Lisboa:

Diante desse problema, Hobbes parece fazer face a uma dupla perspectiva de respostas possíveis: de um lado, certa concepção irracionalista que repousa sobre a hipótese segundo a qual as relações morais e políticas não podem ser organizadas a partir de uma ordenação racional. De outro, uma concepção ultra-racionalista que se apoia sobre a 
hipótese de que existe um procedimento para se estabelecer, apenas pela razão, uma ordem jurídica objetivamente válida (LISBOA, 2008, 116).

Neste texto, pretendemos tratar da relação entre ciência e autoridade sob dois aspectos: aquele da justificação normativa da autoridade e aquele das decisões do soberano acerca da instituição do certo e do errado no âmbito da lei civil. Pretendemos questionar a respeito do papel da ciência e da verdade na justificação da autoridade civil e no fundamento da normatividade das leis e investigar em que medida as decisões do soberano encontram algum respaldo no suposto conhecimento científico acerca dos eventos do mundo e da natureza humana. Com respeito a este último ponto, cabe perguntar, nos referindo a um texto de Gerard Lebrun (2006), se compete ao soberano instituir a verdade ou meramente de descobri-la e utilizá-la como guia para a promulgação da lei civil.

Nossa intenção principal é elencar alguns elementos que possam demonstrar que a tese da auctoritas facit legem não implica o abandono da racionalidade, argumentando que não apenas a justificação da autoridade, mas o próprio processo legislativo do soberano segue um conjunto de princípios racionais. Para tanto, o texto apresenta quatro momentos argumentativos: no primeiro, apresentamos o problema da impossibilidade de acordos em torno dos conceitos morais fundamentais como característica da condição natural; no segundo, apresentamos a noção hobbesiana de racionalidade como cálculo, buscando apontar a impossibilidade de resolver o problema do acordo moral apelando exclusivamente para a razão individual; no terceiro, tratamos o problema da noção voluntarista de lei expressa na tese da auctoritas facit legem a partir do contexto da relação entre os conceitos de auctorictas e potestas; por fim, na última parte do texto, elencamos alguns argumentos, obtidos especialmente da análise dos capítulos XXVII e XXX do Leviatã, para mostrar que a tese da auctorictas facit legem não implica o abandono da racionalidade no processo de instauração da lei positiva.

\section{Da anarquia de significados à regulação do sentido ${ }^{4}$}

Richard Tuck ${ }^{5}$ tem insistido que a causa da guerra na filosofia hobbesiana está relacionada mais com um conflito de crenças do que com um conflito de desejos. Esta interpretação nos remete imediatamente para o problema levantado por Hobbes no capítulo VI do Leviatã, a respeito da impossibilidade de um acordo sobre as noções de bem e mal, certo e errado, na ausência de uma autoridade política. Dado que para Hobbes as paixões são fundamentalmente uma opinião sobre como as coisas nos afetam, é 
possível compreender que o problema da causa da guerra de todos contra todos já aparece no capítulo VI, pois é no contexto das paixões que o conflito de opiniões se estabelece.

Logo após definir as paixões como movimentos voluntários no interior do corpo, cuja direção determina se o movimento pode ser chamado de apetite ou aversão, Hobbes define as noções de bem e mal como nomes dados aos objetos das paixões:

Mas seja qual for o objeto do apetite ou desejo de qualquer Homem, esse objeto é aquele a que cada um chama bom; ao objeto de seu ódio e aversão chama mau, e ao de seu desprezo chama vil e indigno. Pois as palavras "bom" e "mau" e "desprezível" são sempre usadas em relação à pessoa que as usa (HOBBES, 1997, 58).

Esta concepção, que tem sido chamada de subjetivista por muitos intérpretes, ${ }^{6}$ apresenta a origem dos termos morais fundamentais a partir do fluxo inconstante das paixões, tendo como consequência a dificuldade de um acordo estável em torno de tais termos. O problema do acordo moral é apresentado do seguinte modo:

Não há nada que o seja simples e absolutamente, nem há qualquer regra comum do bem e do mal, que possa ser extraída da natureza dos próprios objetos. Ela só pode ser tirada da pessoa de cada um (quando não há estado) ou então (num Estado) da pessoa que representa cada um (HOBBES, 1997, 58).

Na medida em que não há nada bom ou mau em si mesmo, dado que não há o summum bonum "do qual se falava nos livros dos antigos filósofos morais" (HOBBES, 1997, 91), por natureza, as noções de bem e mal dependem exclusivamente do movimento das paixões, e se encontram, portanto, sujeitas à inconstância do fluxo do desejo, que se origina na maior parte das vezes do movimento advindo dos objetos externos, que nunca afetam os homens da mesma maneira, pois:

Dado que a constituição do corpo de um homem se encontra em constante modificação, é impossível que as mesmas coisas nele provoquem sempre os mesmos apetites e aversões, e muito menos é possível que todos os homens coincidam no desejo de um só e mesmo objeto (HOBBES, 1997, 58). 
Estes argumentos já anunciam a necessidade do Estado para a regulação da vida em sociedade. Somente um poder soberano pode dar conta de resolver um problema que, em si mesmo, é insolúvel. Sem este poder comum que defina os termos morais básicos, impera o desacordo que origina necessariamente o conflito. O problema fundamental do estado natural, portanto, não é falta de segurança, mas a impossibilidade de um acordo que possa gerar algum tipo de estabilidade para a vida social. Tratase, sobretudo, do problema do conflito de opiniões. Não por acaso, no capítulo sobre o estado de natureza, o mesmo argumento é retomado para tratar da guerra de todos contra todos:

O bem e o mal são diferentes nomes conforme os diferentes temperamentos, costume e doutrinas dos homens. $\mathrm{E}$ os homens diversos não divergem apenas, em seu julgamento, quanto às sensações do que é agradável ou desagradável ao gosto, ao olfato, ao ouvido, ao tato e à vista, divergem também ao que é agradável ou desagradável à razão, nas ações da vida cotidiana. Mais, o mesmo homem, em momentos diferentes, diverge de si mesmo, às vezes louvando, isto é, chamando bom, àquilo mesmo que outras vezes despreza e a que chama mau. Daqui procedem disputas, controvérsias, e finalmente a guerra (HOBBES, 1997, 132).

Onde não há autoridade comum, não é possível existir regra comum sobre o certo e errado e o conflito de opiniões será permanente. 0 argumento da necessidade do Estado tem aqui sua premissa básica. Conforme Hobbes afirma no De Cive: "não há doutrinas autênticas referentes ao certo e errado, bem e mal, além das leis constituídas em cada reino e governo" (HOBBES, 2002, 99). O Estado, portanto, torna-se o agente instituidor de uma linguagem moral válida, de um critério do certo e errado, que será a lei. Conforme Hampton:

A definição subjetivista de bem no capítulo 6 do Leviatã pode ser lida como um modo de dizer que não há definições naturais desses termos as quais os homens possam aceitar, e que o soberano frequentemente é apresentado como necessário para definir verdades morais que não existem naturalmente $(1986,48)$.

Richard Tuck (1989) afirma que Hobbes, ao perceber que a questão sobre o bem e mal era impossível de ser resolvida, abandonou a discussão sobre a instituição destes termos, passando a tratar da questão do direito, 
buscando na teoria dos direitos naturais um caminho para a solução do conflito moral. Contudo, dada a sua noção de direito e lei, tal caminho, por si mesmo, diferente de Grotius, não dá conta de resolver o problema do ceticismo, uma vez que o próprio direito natural, enquanto liberdade de se fazer o que se quer para a autopreservação, é envolvido na dinâmica da guerra. Assim, a solução de Hobbes, para Tuck (1989), é política. Enquanto persistir o direito natural como liberdade de se fazer o que se quiser, o conflito não se resolve. O problema é que o direito natural continua, no estado de natureza, submetido ao julgamento privado. Desse modo, é necessário que os indivíduos submetam a sua vontade à vontade soberana, o seu julgamento privado ao julgamento do soberano. O problema que se apresenta, desta maneira, diz respeito ao estatuto próprio da solução política. De um lado, a proposta de Hobbes de elaborar uma filosofia civil, isto é, um conhecimento da política fundado no método científico, nos conduz para a concepção segundo a qual há uma ordenação racional capaz de orientar a vida política. De outro lado, a tese da autorictas facit legem parece indicar que a única saída possível é a submissão à vontade arbitrária do soberano, sendo esta vontade arbitrária em si mesma a fonte da legitimidade das decisões do soberano.

\section{Razão, ciência e política}

Se do ponto de vista das próprias coisas é impossível derivar qualquer noção objetiva de bem e mal ou certo e errado, do ponto de vista da própria concepção de razão, o texto de Hobbes muitas vezes também parece conduzir a um limite intrínseco à capacidade racional de estabelecer uma solução definitiva para o problema, o que dificulta atribuirmos a Hobbes uma noção clara de razão prática. Hobbes não concebe a razão como uma faculdade teleologicamente orientada, como em Aristóteles, capaz de colocar fins aos homens. Para o filósofo inglês, o papel específico da razão é de estabelecer relações entre nomes, enquanto os fins são dados exclusivamente pelo desejo.

Se olharmos para o Leviatã, observamos mais claramente a concepção hobbesiana de razão como uma capacidade adquirida, originada com invenção da linguagem:

Por isto torna-se visível que a razão não nasce conosco como a sensação e a memória nem é adquirida apenas pela experiência, como a prudência, mas obtida pela indústria, primeiro através de uma adequada imposição de nomes, e em segundo lugar através de um método bom e ordenado de 
passar dos elementos, que são nomes, para as asserções feitas por conexão de um deles com o outro, e daí para silogismos, que são as conexões de uma asserção com outra (HOBBES, 1997, 54).

Temos, nessa passagem, a definição mais elaborada de razão que Hobbes nos fornece e que apresenta suas características mais fundamentais. A razão é artificial: um tipo de cálculo que depende do uso da linguagem. Essa concepção se encontra em outras obras, como no De Corpore, ${ }^{7}$ por exemplo. No Início do capítulo $\mathrm{V}$ do Leviatã, a razão é definida como "cálculo (isto é, adição e subtração) das consequências de nomes gerais estabelecidos para marcar e significar nossos pensamentos" (HOBBES, 1997, 51). A razão somente pode surgir a partir da aquisição da linguagem. Não é, portanto, natural, tendo em vista que a linguagem é uma invenção. ${ }^{8}$

Esta concepção de racionalidade dificulta pensarmos o problema da normatividade em termos puramente jusnaturalistas, ainda que Hobbes recorra à linguagem da lei natural e efetivamente afirme que a verdadeira filosofia é a ciência das leis de natureza (HOBBES, 1997). Contudo, dadas as mudanças radicais na sua concepção de razão, é problemático considerar as leis naturais como fonte da autoridade política. Hobbes é enfático ao afirmar que as leis de natureza não são propriamente leis, mas teoremas da razão, não originando propriamente obrigatoriedade no estado de natureza. Nesse sentido, de acordo com Lang e Slomp $(2016,5)$ "a teoria de Hobbes representa uma grande mudança em relação às teorias antigas e medievais, na medida em que a lei da natureza de Hobbes não está mais ligada à noção de uma ordem cósmica, nem ancorada ao conhecimento indiscutível".

Contudo, se por um lado a concepção de razão como cálculo parece dificultar a atribuição a Hobbes de uma noção de razão prática capaz de justificar os enunciados normativos da autoridade política, por outro, o filósofo encontra na passagem da prudência (o mero cálculo com imagens) para a razão (cálculo com nomes) o estabelecimento da necessidade e universalidade que falta ao conhecimento da experiência. A distinção entre prudência e razão ocupa um lugar de destaque na estrutura argumentativa do Leviatã, uma vez que é sobre ela que Hobbes busca justificar a tese de um conhecimento seguro para a política.

É possível questionar se a passagem da prudência para a razão tem o mesmo estatuto na política do que tem na epistemologia. Ou seja, se do âmbito epistemológico, a passagem da prudência para a razão garante a possibilidade da necessidade e da universalidade, do âmbito político tal condição parece ser impossível, uma vez que o soberano parece decidir 
arbitrariamente. Porém, é necessário considerar que Hobbes repetidas vezes considera a política como tendo um estatuto científico superior às ciências empíricas, na medida em que, assim como na geometria, nós somos seus próprios autores e, portanto, conhecemos a origem do movimento, isto é, conhecemos as causas. Por essa ótica, a política teria um nível de rigor superior no que concerne à necessidade e universalidade, justamente por operar com o método geométrico de modo exemplar. ${ }^{9}$ No âmbito político, podemos compreender o processo de instauração do Estado como um processo análogo à passagem da prudência para a razão. A instituição do Estado se constitui na instauração de um conjunto de relações jurídicas que são racionais, as quais substituem justamente um conjunto de relações de puro poder do estado de natureza. Deste modo, no âmbito do estado de natureza, o conjunto de relações de poder se encontra justamente na esfera da prudência, do cálculo mental. Já no Estado Civil, não apenas as relações são jurídicas, mas a própria soberania é constituída desde o início no campo jurídico na medida em que sua origem está fundada no contrato. É neste domínio que o caráter racional, compreendido como a retirada de consequências a partir do cálculo com nomes, se expressa. Por isso, no capítulo sobre a razão e a ciência, Hobbes frisa o caráter científico e racional da política: "Os escritores de política adicionam em conjunto pactos para descobrir os deveres dos homens, e os juristas leis e fatos para descobrir o que é certo e errado nas ações dos homens privados" (HOBBES, 1997, 51).

Não há dúvidas, portanto, do caráter eminentemente racional que Hobbes procura conferir ao conhecimento da política e à soberania mais especificamente. É justamente neste sentido que a tese da auctorictas facit legem parece colocar um problema para tal concepção. O voluntarismo característico da noção de lei parece conduzir a tese hobbesiana para um campo distante do racionalismo que perpassa a estrutura jurídica que justifica a soberania.

\section{Auctoritas, potestas e a teoria do comando}

A adesão por parte de Hobbes a um modelo claramente voluntarista de lei parece contrastar com a tentativa de fundar a soberania a partir de um modelo jurídico que se estrutura na razão e na ciência. É fundamental, neste sentido, considerarmos que Hobbes adota um modelo segundo o qual a lei é propriamente o comando daquele que tem direito de mando (HOBBES, 1997). A lei, portanto, não expressa mais uma ordem natural, mas a vontade daquele que a comanda. Os estudos de Michael Stolleis (2008) e George Duke (2014) mostram que o voluntarismo característico 
da teoria da justificação da autoridade política hobbesiana ocorre num contexto de mudança da legitimação do poder político, cujo desenvolvimento é expresso significativamente na relação entre os conceitos de auctoritas e potestas. Tais conceitos eram concebidos de modo nitidamente distinto até o início da modernidade. No direito romano, o termo auctoritas designa a prerrogativa do senado de dar conselhos aos magistrados ou portadores do poder político (AGAMBEN, 2004). Segundo Duke, esta noção de auctoritas "retém uma forte conexão epistemológica com argumentação, sugerindo uma dependência sobre uma fundamentação anterior sobre a verdade" $(2014,616)$. Já o termo potestas, por contraste, designa o poder político derivado da vontade do povo e manifestado na forma de comandos. Carl Schmitt, também insiste nesta distinção afirmando que "O Senado tinha auctoritas, mas é do povo que dependiam a potestas e o imperium" (apud AGAMBEN, 2004, 116).

É bastante perceptível que na obra de Hobbes ocorre uma erosão da distinção entre os dois conceitos, ao ponto de serem utilizados muitas vezes de modo intercambiável. Esta mudança semântica que acabou por confluir o significado de dois termos originalmente distintos parece ser característica própria da filosofia jurídica que se desenvolve a partir da modernidade, expressando-se no aparecimento de uma concepção muitas vezes chamada de teoria do comando, segundo a qual, a justificação normativa da lei é o comando da autoridade. Tal posição, efetivamente, parece ser a de Hobbes, que no Leviatã afirma "(...) ao passo que a lei, em sentido próprio, é a palavra daquele que tem direito de mando sobre os outros" (HOBBES, 1997, 113). Este processo de apagamento da distinção entre auctoritas e potestas, característico da modernidade, tem sido apontado por autores como Agamben e Arendt como problemático. Hannah Arendt, em seu ensaio O que é autoridade, lamenta a confusão entre autoridade e poder operada na moderna teoria do Estado, ressaltando, em sua interpretação, a distinção entre os dois conceitos: "Visto que a autoridade sempre exige obediência, ela é comumente confundida com alguma forma de poder ou violência. Contudo, a autoridade exclui a utilização de meios externos de coerção; onde a força é usada, a autoridade em si mesmo fracassou" (ARENDT, 2003, 129).

Contudo, não há consenso em torno do fato de a auctoritas expressar um sentido epistemológico que faltaria à potestas, conforme sugere a interpretação de Duke. Os estudos de Hanna Arendt e Agamben apontam para uma outra direção, ressaltando que o conceito de auctoritas está relacionado mais propriamente com uma noção de posição hierárquica do que propriamente com uma noção de superioridade epistemológica. Arendt afirma que "a relação autoritária entre o que manda e o que obedece 
não se assenta nem na razão comum nem no poder do que manda; o que eles possuem em comum é a própria hierarquia" (ARENDT, 2003, 129). Agamben (2004) também ressalta que a origem da noção, tanto no direito público quanto privado, está associada à posição daquele que detém a auctoritas. No direito privado, ela é derivada diretamente da condição de pater. No direito público, o que caracteriza a auctoritas é sua capacidade de, em circunstâncias especiais, suspender a potestas (AGAMBEN, 2004). Nessa direção, portanto, parece difícil afirmar, como defende Duke, que haveria uma espécie de sentido epistemológico na noção de auctoritas.

De todo modo, no caso específico de Hobbes, é explícito que a fonte da legitimidade da autoridade não é sua suposta superioridade epistemológica sobre os demais, como se aquele que detém a soberania possuísse uma capacidade superior de descobrir as verdades morais às quais os demais não têm acesso. De modo muito diferente, a legitimidade da autoridade deriva, no Leviatã, do processo de autorização, fundado na dinâmica autor/ator que concebe, em última instância, a legitimidade da autoridade como derivando da própria vontade dos indivíduos. É importante ressaltar, também, que o processo de autorização não tem como base uma premissa sobre a superioridade epistêmica do autorizado sobre os autores da autorização. Até porque, para Hobbes, em completa concordância com o cartesianismo de seu tempo, a condição própria da natureza humana é de igualdade intelectual, ${ }^{10}$ sendo apenas o método, o estudo, o esforço, que propriamente podem estabelecer uma distinção intelectual entre os indivíduos. Contudo, no processo de autorização, nem mesmo este método é invocado para alegar qualquer tipo de superioridade ou capacidade especial do autorizado. Hobbes, efetivamente, não se interessa pelas características naturais e intelectuais do autorizado, uma vez que está preocupado com a soberania enquanto pessoa artificial. O problema, para Hobbes, é outro. A noção de autorização, que legitima a autoridade, vem resolver justamente o problema do conflito de opiniões do estado de natureza. Este conflito, para Hobbes, não é resolvido simplesmente apelando para a superioridade intelectual de alguém - pois, efetivamente, tal condição não parece existir -, mas apelando para a noção de unidade:

Uma multidão de homens é transformada em uma pessoa quando é representada por um só homem ou pessoa, de maneira que tal seja feito com o consentimento de cada um dos que constituem essa multidão. Porque é a unidade do representante e não a unidade do representado que faz que a pessoa seja uma (HOBBES, 1997, 137). 
O processo de autorização se justifica na medida em que resolve os problemas apontados por Hobbes sobre a dificuldade de unidade em torno das avaliações morais no estado de natureza, fundamentalmente o problema do conflito de opiniões. Dado que não existe nenhum summum bonum, dado que da natureza das coisas não se pode derivar nenhuma regra do bem e do mal, e nessa condição, conduzidos pelas paixões, os homens tendem a conflitar, a autorização permite finalmente a conquista da unidade e da definição comum do bem e do mal e do certo e do errado através da instituição da lei civil. Conforme ressalta Duke, "a autorização retira as fontes da autoridade da tradição e dos costumes em favor de uma concepção fundada nos direitos dos indivíduos motivados por autointeresse" (DUKE, 2014, 618).

\section{A racionalidade das decisões políticas}

Diante destas questões, cabe investigar mais especificamente o procedimento legislativo do soberano. Este procedimento deve seguir alguma regra racionalmente justificada para que seja considerado legítimo? Ou, contrariamente, toda decisão legislativa do soberano é por si só legítima em virtude de sua autoridade derivada do pacto de autorização? E ainda: se há alguma regra para este procedimento legislativo, é possível dizer que tal regra segue a concepção de ciência moral compreendida como dedução das leis naturais? Em última instância trata-se de saber se, ao legislar, o soberano o faz como um cientista das leis de natureza que segue um critério pré-determinado em relação à sua vontade. Se há tal critério, significa que a decisão soberana não é puramente arbitrária, mas segue um padrão que Ihe serve como uma espécie de limite?

É especialmente nos capítulos XXVI (Das leis civis) e XXX (Do cargo do soberano representante) do Leviatã que encontramos algumas considerações sobre a questão, ainda que bastante generalistas.

Quando atentamos para o capítulo sobre a lei civil, há uma passagem fundamental que não deixa de gerar alguma perplexidade ao leitor. Hobbes afirma que a lei civil não pode ser contrária à razão. Esta declaração expressa o caráter racional envolvido no procedimento legislativo. Contudo, não se trata, segue dizendo Hobbes, de nenhuma razão privada, caso contrário haveria tantas contradições nas leis como há nas escolas:

Nem tampouco (como pretende Sir Edward Coke) de uma perfeição artificial da razão, obtida através do estudo e da observação e experiência (como era a dele). (...) Portanto, o que faz a lei não é aquela juris prudentia, ou sabedoria dos 
juízes subordinados, mas a razão deste homem artificial, o Estado e suas ordens (HOBBES, 1997, 210).

Esta passagem não deixa de apresentar a questão de modo ambíguo, uma vez que por um lado a lei não pode ser contra a razão, contudo não pode ser qualquer razão, mas apenas a razão do homem artificial, do soberano. Cabe perguntar por que esta razão do Estado é superior às demais, e efetivamente, não parece haver nenhuma justificativa fundada na superioridade epistemológica da razão do soberano. Neste sentido, fica evidente que Hobbes não está contando com uma capacidade de raciocínio superior da pessoa natural que ocupa a soberania. A justificativa para a condição especial que a razão do Estado ocupa é apresentada no mesmo parágrafo: "E sendo o Estado, em seu representante, uma só pessoa, não é fácil surgir uma contradição nas leis, e quando tal acontece a mesma razão é capaz, por intepretação ou alteração, de eliminar a contradição" (HOBBES, 1997, 210). Esta justificativa expressa toda a ambiguidade da relação entre ciência e política sobre a qual estamos tratando aqui. O que confere um status diferenciado à razão do Estado não é uma qualidade intrínseca à capacidade de raciocínio da pessoa natural do soberano, mas uma condição exterior, que diz respeito à circunstância do procedimento. 0 que muda com a instituição do Estado são as circunstâncias do procedimento racional a respeito do processo legislativo: ao invés de várias pessoas naturais raciocinando, há apenas um raciocínio, aquele do Estado. E o que confere mais segurança aos resultados neste caso é justamente o fato de que, sendo apenas um único raciocínio em jogo, é mais fácil prever e resolver as eventuais inconsistências e contradições deste raciocínio. A lição de Hobbes aqui reflete vários outros momentos da sua obra: com várias pessoas disputando através do raciocínio, a chance de indeterminação e confusão é sempre maior. Por isso, a saída não é escolher aquele supostamente mais sábio ou mais inteligente, mas extinguir a disputa com a eliminação das várias fontes de provável confusão, optandose por adotar um único juízo como meio para atingir a estabilidade.

Assim, podemos compreender melhor a ideia de que a autoridade faz a lei. Não significa que a autoridade não deve respeitar a verdade e a razão, mas sim que a verdade é em si mesma insuficiente para conceder legitimidade à lei, uma vez que as várias racionalidades em disputa seguiriam impedindo a estabilidade do processo legislativo. É necessário, portanto, a autoridade do soberano para que se coloque fim às disputas, do mesmo modo que é necessária sua autoridade para colocar fim à disputa de opiniões no estado de natureza. Não por acaso, esta passagem evoca a discussão sobre as associações de defesa mútua no capítulo XVII do 
Leviatã. No caso destas associações, se as ações de cada um forem determinadas pelo juízo individual e pelas paixões de cada um, não há esperança de que uma associação possa conferir segurança. ${ }^{11}$ Do mesmo modo, no procedimento da instauração da lei, não é possível confiar no juízo individual dos magistrados, ainda que este juízo possa ser extremamente desenvolvido.

Deste modo, a intenção de Hobbes é justamente eliminar a multiplicidade. Sua preocupação não é somente com a multiplicidade de opiniões do estado de natureza, mas também com a multiplicidade de razões em disputa no processo legislativo. A solução para isso está na tese da autorização, através da qual toda multiplicidade finalmente pode ser reduzida à unidade, conferindo assim a estabilidade necessária à vida social.

Ainda no capítulo sobre a lei civil, Hobbes apresenta um conjunto de considerações que expressam o aspecto voluntarista e positivista de sua concepção de lei, e demonstram o caráter terminativo da decisão do soberano. As leis civis são as regras do justo e do injusto, o que demonstra que Hobbes está retomando os problemas que foram apresentados nos capítulos VI e XIII a respeito da impossibilidade de se encontrar o justo e o injusto a partir das paixões e dos raciocínios individuais dos homens. 0 soberano é o único legislador, a única fonte da lei. Nem o costume, nem a lei natural em si mesma, nem a sabedoria dos juízes pode ser a fonte da lei. E ainda que diga que a lei natural e civil contém-se uma à outra, o que por vezes tem sido interpretado como uma declaração sobre a normatividade da lei natural, ${ }^{12}$ esta afirmação não parece justificar tal interpretação, pois logo a seguir, o autor afirma, repetindo o que já disse no capítulo $X V$, que as leis naturais não são propriamente leis, mas apenas qualidades que dispõem os homens para a paz e declara enfaticamente que: "Só depois de instituído o Estado elas efetivamente se tornam leis, nunca antes", pois "para declarar, nas dissenções entre particulares, o que é equidade, o que é justiça e o que é virtude moral, e torná-las obrigatórias são necessárias as ordenações do poder soberano" (HOBBES, 1997, 209).

Defendemos, contudo, que tais considerações não implicam o abandono da razão e da ciência, pois o processo de instituição da lei a pressupõe.

Se observarmos o capítulo sobre o cargo (office) do soberano, esta ambiguidade não desaparece, sendo expressada no próprio título, uma vez que office remete ao termo latino officis, denotando um sentido normativo para o termo. Contudo, é difícil falarmos em deveres do soberano, tendo em vista que Hobbes declara em vários lugares que o soberano está acima da lei sendo, portanto, infundado falar que ele tenha propriamente obrigações para com os súditos. Além disso, como o soberano 
não fez propriamente parte do pacto, ${ }^{13}$ também é difícil pensar em qualquer forma de dever advinda da obrigação contratual. Neste capítulo, Hobbes apresenta algumas poucas indicações de quais seriam tais funções que o soberano deve cumprir: fundamentalmente, precisa garantir a segurança, manter a soberania, fazer boas leis e informá-las claramente aos súditos. Neste sentido, há uma declaração enfática abrindo o capítulo: "O cargo (office) do soberano (seja ele um monarca ou assembleia) consiste no objetivo para o qual Ihe foi confiado o poder, nomeadamente a obtenção da segurança do povo" (HOBBES, 1997, 251). A garantia da segurança do povo, sobre a qual Hobbes enfatiza ser mais do que a mera preservação, exige um conjunto de medidas que norteiam a ação do soberano: "por uma providência geral, contida em instrução pública, quer de doutrina quer de exemplo, e na feitura e execução de boas leis, às quais os indivíduos podem recorrer nos seus casos" (HOBBES, 1997, 251). Dizer que a autoridade faz a lei não parece, portanto, implicar no abandono da razão em nome de um arbítrio irracional. Ao contrário, Hobbes aponta sempre a necessidade de regras racionais que orientam o processo decisório do soberano, sempre tendo em vista a manutenção da estabilidade e principalmente da continuidade do Estado. E nesse sentido, as indicações da razão segundo as quais a paz é boa e a respeito das virtudes morais que apontam os melhores caminhos para a paz seguem sendo princípios de orientação para o soberano. Nesse aspecto, há claramente um princípio racional de cálculo meio fim operando no processo legislativo. Assim, as leis civis podem ser entendidas como os melhores meios descobertos pela razão para atingir o fim da associação política: a sobrevivência. O soberano é o intérprete definitivo das leis de natureza, diz Hobbes, mas esta interpretação deve seguir um procedimento também racional. Contudo, não se trata da razão privada do soberano enquanto pessoa natural, mas sim da razão do soberano enquanto pessoa artificial. Esta pessoa tem seu fundamento no pacto de autorização e como tal deve, em sua tarefa de interpretar a lei natural e instituir a lei civil, ter como norte o objetivo fundamental do pacto de autorização: a garantia da preservação dos contratantes. Assim, em várias passagens Hobbes (1997) declara que na tarefa legislativa deve-se buscar a justiça e imparcialidade na medida em que tais condições são fundamentais para garantir a continuidade do Estado. Podemos concluir, portanto, que aqui a ciência moral de Hobbes, concebida como a dedução das leis de natureza, é fundamental para orientar o processo de interpretação das leis de natureza e a instituição da lei civil. Ainda que não seja o fato de o conteúdo da lei ser verdadeiro que torne a lei obrigatória, é nesta racionalidade fundamental da ciência das leis de natureza que o processo legislativo do soberano deve se fundamentar. 


\section{Notas}

${ }^{1}$ Professor do Curso de Filosofia da Universidade Federal da Fronteira Sul (UFFS). Doutor em Filosofia pela Universidade Federal de Santa Catarina (UFSC). Realizou estágio pós-doutoral na Universidade de São Paulo (USP).

2 A sistematicidade do projeto hobbesiano levado a cabo nos Elementae e a dependência da política relativamente à física já foi bastante questionada ao longo do século $X X$, tendo começado já com os estudos de Leo Strauss. Independente desta questão, contudo, é inegável que Hobbes apresenta uma tentativa de fundar a política sobre o conhecimento científico e racional, projeto este que é continuamente anunciado ao longo da obra. Para uma discussão mais detalhada, ver Sorell (1986) e Brandt (1928).

3 É necessário considerar que a vontade, para Hobbes, não é um apetite racional ou uma faculdade do querer racional, como a tradição escolástica considerava. A vontade, para o filósofo, é o último apetite que prepondera no processo de deliberação. Fundamentalmente, portanto, a vontade se identifica com o desejo. Assim: "A definição da vontade vulgarmente dada pelas Escolas, como apetite racional, não é aceitável" (HOBBES, 1997, 63).

${ }^{4}$ Esta expressão é utilizada por Sheldon Wolin, em Hobbes y la tradición épica de la teoria política (2005).

${ }^{5}$ Especialmente em Hobbes's Moral Philosophy (1996) e Hobbes (1989).

6 Especialmente Jean Hampton em Hobbes and the Social Contract Tradition (1986) e David Gauthier em The Logic of Leviathan: The moral and Political Theory of Thomas Hobbes (1969).

7 "Por raciocínio entendo cálculo. Ora, Calcular é ou coletar a soma de muitas coisas adicionadas conjuntamente, ou conhecer o que resta quando uma coisa é retirada de outra" (HOBBES, 2010, 21).

8 "Todavia, a mais nobre e útil de todas as invenções foi a da linguagem, que consiste em nomes ou apelações e em suas conexões, pelas quais os homens registram seus pensamentos, os recordam depois de passarem, e também os usam entre si para a utilidade e conversa recíproca" (HOBBES, 1997, 43).

9 Neste sentido, ver especialmente De Corpore, I, I, 9 e a tábua das ciências do capítulo IX do Leviatã. Para uma discussão sobre o caráter hipotético das ciências naturais, ver Jesseph (1999).

10 Hobbes, evidentemente, não defende uma igualdade absoluta, admitindo que há uma distinção natural no que diz respeito à agilidade de passar de uma imagem para outra no raciocínio mental. Contudo, tal desigualdade, na condição natural não desempenha nenhum papel relevante: "a diferença entre um e outro homem não é suficientemente considerável para que qualquer um possa com base nela 
reclamar qualquer benefício a que outro não possa também aspirar, tal como ele" (HOBBES, 1997, 107).

11 "Mesmo que haja uma multidão, se as ações de cada um dos que a compõe forem determinadas segundo o juízo individual e os apetites individuais de cada um, não poderá esperar-se que ela seja capaz de dar defesa e proteção a ninguém, seja contra o inimigo comum, seja contra as injúrias feitas uns aos outros" (HOBBES, 1997, 142).

12 Neste sentido, especialmente as interpretações de Taylor (1938) e Warrender (1957).

13 "Em segundo lugar, dado que o direito de representar a pessoa de todos é conferido ao que é tornado soberano mediante um pacto celebrado apenas entre cada um e cada um, e não entre o soberano e cada um dos outros, não pode haver quebra do pacto da parte do soberano (...)" (HOBBES, 1997, 146). 


\section{Referências}

AGAMBEN, G. Estado de exceção. São Paulo: Boitempo, 2004.

ARENDT, H. Entre o passado e o futuro. São Paulo: Perspectiva, 2003.

BRANDT, T. Thomas Hobbes' mechanical conception of nature. London: Librarie Hachette, 1928.

DASTON, L.; STOLLEIS, M (org.). Natural law and laws of nature in early modern Europe: jurisprudence, theology, moral and natural philosophy. Surray: Ashgate, 2008.

DUKE, G. Hobbes on authority, pratical reason and truth. Law and philosophy, v. 33, p. 605-627, 2014.

GAUTHIER. D. The logic of leviathan: the moral and political theory of Thomas Hobbes. Oxford: Clarendon Press, 1969.

HAMPTON, J. Hobbes and the social contract tradition. Cambridge: Cambridge University Press, 1986.

HOBBES, T. Diálogo entre um filósofo e um jurista. Tradução: Maria Cristina Guimarães Cupertino. São Paulo: Landy Editora, 2004.

HOBBES, T. Do cidadão. Tradução: Renato Janine Ribeiro. São Paulo: Martins Fontes, 2002.

HOOBES, T. Do corpo. Parte I: cálculo ou lógica. Tradução: Maria Isabel Limongi e Viviane de Castilho Moreira. Campinas: Ed. Unicamp, 2010.

HOBBES, T. Leviatã. Tradução: João Paulo Monteiro e Maria Beatriz Nizza da Silva. São Paulo: Abril, 1997.

HOBBES, T. Leviathan. Cambridge: Cambridge University Press, 1996.

HOBBES, T. Man and citizen (de homine and de cive). Edited by Bernard Gert. Hackett Publishing Company: Indianápolis; Cambridge, 1991.

JESSEPH, D. M. Hobbes and the method of natural science. In: SORELL, T. (ed.). The Cambridge companion to Hobbes. Cambridge: Cambridge University Press, 1999. p. 86-107. 
LANG, A. F.; SLOMP, G. Thomas Hobbes: theorist of the law. Critical review of international social and political philosophy, vol. 19, n.1, p. 1-11, 2016.

LEBRUN, G. Hobbes e a instituição da verdade. In: LEBRUN, G. A filosofia e sua história. São Paulo: Cosacnaify, 2006, p. 297-327.

LISBOA, W. B. Razão, história e justificação da lei civil segundo Thomas Hobbes. Revista sequência, Florianópolis, n. 57, p. 115-130, dez. 2008.

SORELL, T. Hobbes. London: Routledge, 1991.

SORELL, T. Hobbes's moral philosophy. In: SPRINGBORG, P. (Ed.). The Cambridge companion to Hobbes's leviathan. Cambridge: Cambridge University Press, 2007. p. 128-153.

SORELL, T. (Ed.). The Cambridge companion to Hobbes. Cambridge: Cambridge University Press, 1996.

STOLLEIS, M. The legitimation of law through god, tradition, will, nature and constitution. In: DASTON, L.; STOLLEIS, M (Org.). Natural law and laws of nature in early modern europe: jurisprudence, theology, moral and natural philosophy. Surray: Ashgate, 2008.

STRAUSS, L. Natural right and history. Chicago: Chicago University Press, 1953.

TAYLOR, A. E. The ethical doctrine of Hobbes. Philosophy, n. 13, p. 406$424,1938$.

TUCK, R. Hobbes's moral philosophy. In: SORELL, T. (ed.). The Cambridge Companion to Hobbes. Cambridge: Cambridge University Press, 1996. p. 175-207.

TUCK, R. Hobbes. São Paulo: Edições Loyola, 1989.

TUCK, R. Natural rights theories. Cambridge: Cambridge University Press, 1979.

WARRENDER, W. The political philosophy of Hobbes: his theory of obligation. Oxford: Clarendon Press, 1957.

WOLIN, S. S. Hobbes y la tradición épica de la teoría política. Madrid: Editorial Foro Interno, 2005. 
Received/Recebido: 19/11/21 Approved/Aprovado: 01/12/20 